\title{
THE UTILIZATION OF MOUTH-PROTECTORS BY FRESHMAN FOOTBALL PLAYERS
}

\author{
By William C. Godwin, DDS. MS. ${ }^{*}$ Robert A. Bagramian, DDS, DrPh, ${ }^{* *}$ \\ and Emerson Robinson, DDS, $\mathrm{MPH}^{* * *}$
}

The writers of this report question the conclusion that oral injuries now have been eliminated for players on football teams.

Since the National Alliance Football Rules Committee issued a mandate in 1962 to require that football players in high school and junior colleges wear mouth-protectors, oral injuries virtually have been eliminated in this group of more than $1,000,000$ players.' The authoritative articles on the advantages provided by mouth-protectors indicate, prior to their use, that dental and mouth injuries comprised approximately 50 percent of the total injuries from football. Introduction of face-guards reduced the number by about one-half, and mouth-protectors practically have eliminated the rest. In the year 1967 alone, more than 25,000 to 50,000 injuries to players were estimated to have been prevented by the use of mouth-protectors. ${ }^{2}$ Use of the mouth-protectors also has been shown to be a factor in reducing the incidence of concussions from a blow to the chin. ${ }^{2,3}$ An unexpected result has been an observation that the number of injuries to the neck also seem to be reduced and relief provided from chronic neck-problems. ${ }^{3}$

Considerable research has been reported on the development and testing for an optimal mouthguard. The brands which have been produced and introduced can be classified in three categories: (1) stock-protectors which come in limited standard sizes and molds and usually are purchased at sporting-goods stores or drugstores; (2) mouth-formed protectors which usually consist of an outer shell, either rigid or nonrigid, with an inner plastic material which, properly conditioned, can be introduced directly into the mouth and the imprints of the teeth recorded; and (3) custom-formed protectors fabricated on a model of the individual's mouth and usually fitted at a later appointment. Over a period of time, opinion has varied considerably about which type of protector provides the most protection and comfort. ${ }^{2,3,4,5,6,7} \mathrm{~A}$ consensus seems to exist that all offer some type of protection and all offer some degree of this protection. The custom-formed protector generally is accepted as the most desirable and the stock-protector as the least desirable.

\section{Method of Current Investigation}

In order to determine the extent of the past use of mouth-protectors, the attitudes toward wearing them when no mandate for their use exists, and the effectiveness when worn, the incoming members of the freshman football team of The University of Michigan were surveyed by a personally administered questionnaire at the beginning of the football seasons for 1970 and 1971. All 38 freshman receiving grants-in-aid in 1970 and all 31 for 1971 completed the questionnaires.

\section{Findings}

The data obtained showed that only five $(7.2$ percent) players had not worn mouth-protectors previously and one only of this group indicated that he was not

\footnotetext{
*Associate Professor of Complete Denture Prosthesis, The University of Michigan, School of Dentistry, Ann Arbor, 48104

**Assistant $P^{3}$ rofessor and Chairman, Departinent of Community Dentistry, same address .

***Assistant Professor of Community Dentistry, same address.
} 
planning to wear one in college. Of the five, one had experienced a cut lip as the only injury to the oral cavity. Five of the total group of players indicated that they were not planning to wear a mouth-protector in college. Two stated that they had problems in breathing, one claimed impairment of his speech, and two merely expressed their dislike for wearing the protectors. Fifty-nine $(85.5$ percent) of the players reported that they had worn a mouth-protector either in junior high or high school and three had worn a protector additionally in sports other than football. Forty-six (66.6 percent) of the players reported that they had worn mouth-protectors all of the time during training for football, and 18 (26.8 percent) had worn them at other times than in games.

Thirty ( 43.4 percent) of the players reported that their coaches exerted the greatest influence on their wearing or not wearing a mouth-protector. Nineteen (27.4 percent) reported that their own decision was the greatest influence. Only two ( 2.9 percent) of the players reported that their dentist exerted the chief motivation. The mouth-adapted type of protector appeared to be the most commonly used, inasmuch as 37 (53.6 percent) reported experience with this type, the experience of the remaining players was about equally divided between the custom- and stock-models. Four players reported that a dentist had helped fabricate their protectors.

Nineteen (27.4 percent) of the 69 players surveyed reported mouth injuries during athletic participation and 22 (31.8 percent) reported friends and teammates who had experienced dental or oral injuries as a result of participation in athletics. Of the nineteen (27.4 percent) who reported personal injuries, seven ( 36.8 percent) were wearing a protector when injured.

The attitudes about an injury to anterior teeth varied. Thirty-one ( 44.9 percent) were badly upset, 26 (37.7 percent) mildly upset, nine (12.0 percent) were indifferent, and one player "did not care." Forty-four (63.7 percent) stated that they thought an oral or dental injury was unlikely to happen to them and the remaining 21 ( 30.4 percent) thought that they might get injured. Of those who stated this possibility of being injured, four (5.7 percent) indicated that they were not planning to wear a mouth-protector, whereas the 44 (63.7 percent) in the group not thinking that an injury would occur, but one was planning not to wear a protector. Of the 69 players surveyed, sixty four $(92.7$ percent) agreed that a mouth-protector would protect their mouth and teeth against injury. Three (4.34 percent) thought that a mouth-protector would not benefit them. Two players did not respond to this question.

Fifteen (21.7 percent) reported concussions from contact sports, and all of these players indicated a desire to wear mouth-protectors. The reaction to visiting a dentist varied-three (4.3 percent) liked to do so, 29 (42.0 percent) said "it's okay," 21 (30.4 percent) expressed indifference, 14 ( 20.7 percent) disliked it, and two (2.9 percent) hated it.

\section{Some Discussion}

The information obtained from the surveys indicated that most of the players thought mouth-protectors offered good protection from injury and they were willing to wear them. The strongest motivation for wearing or not wearing a mouth-protector was the attitude of the coach. The type of mouth-protector most used by these players was the mouth-formed protector, usually adapted by the players themselves. Most of the players felt that an injury to their mouth or teeth was unlikely, but they still preferred to wear the protector. All who had suffered concussions were motivated to wear the mouthguards. Two studies carried out in the laboratory have determined the physical properties of an acceptable mouthguard. ${ }^{8,9}$ The present survey suggests, however, that a controlled study now is required to ascertain the true acceptance and actual attainment of mouthguards. Because of the large number of injuries reported by the players themselves or to their teammates, the conclusion appears obvious that many injuries are not reported and that the articles published which suggest that oral and dental injuries now have been eliminated are premature. 


\section{Bibliography}

1. Heintz, W. D. NCAA again fails to support mouth protector regulations. Am. Dent. A. J., 78:484, Mar. 1969.

2. Heintz, W. D. Mouth protection: a progress report. Am. Dent. A. J., 77:652-6, Sept. 1968.

3. Hickey, J. C. et al. The relation of mouth protectors to cranial pressure and deformation. Am. Dent. A. J., 74:735-40, Mar. 1967.

4. Stenger, J. M., et al. Mouthguards: protection against shock to head, neck, and teeth. Am. Dent. A. J., 69:273-81, Sept. 1964.

5. Gelbier, Stanley. The use and construction of mouth and tooth protectors for contact sports. Brit. Dent. J., 120:533-7, June 7, 1966.

6. Logan, F. E. Prevention of serious injuries; mouthguards for athletes. Ky. Dent. A. J., 18:31-4, July 1966.

7. Sprugt, J. L. Mouth protectors for physical contact sports. So. African Dent. J., 20:324-7, Nov. 1965.

8. Craig, R. G., and Godwin, W. C. Physical properties of materials for custom-made mouth protectors. Mich. Dent. A. J., 49:34-40, Feb. 1967.

9. Godwin, W. C., and Craig, R. G. Stress transmitted through mouth protectors. Am. Dent. A. J., 77:1316-20, Dec. 1968 .

\section{Health Resources Statistics-1970}

Sheldon Starr, Staff Assistant, Division of Health Resources, has prepared the report on "Health Manpower and Health Facilities, 1970," (3.9 million persons employed in the health professions for 1969). The first part of this 362-page publication presents the data on the health occupations. Chapter Eight, 16 pages in length, presents the information on Dentistry and Allied Services as prepared by George L. Crocker, Donald W. Johnson, and Jane H. Priest. For anyone surveying manpower, the information is tremendous. (U.S. Government Printing Office, February 1971, \$3.25)

\section{Announcing a Residency}

The National Institute of Dental Research announces a residency of one-calendaryear in dental public health which is approved by the Council on Dental Education and supervised by a Diplomate of the American Board of Dental Public Health. Research in dental public health will be emphasized to supply expertise in the design of a project, and the principles and procedures of epidemiology, biometry, and processing of data. Candidates apply to Harold R. Englander, Chief, Field Trials Section, Disease Prevention and Therapeutics Branch, National Institute of Dental Research, Bethesda, Maryland, 20014. (Announcement, August, 1971) 